\title{
Antimicrobial Resistance and Virulence of Salmonella spp. From Foods in Mazandaran
}

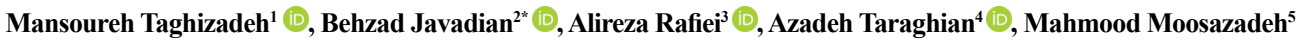 \\ 1. Food Quality Control Laboratory, Mazandaran University of Medical Sciences, Sari, Iran. \\ 2. Amol Faculty of Paramedics, Mazandaran University of Medical Sciences, Sari, Iran. \\ 3. Department of Immunology, Molecular and Cell Biology Research Center, Mazandaran University of Medical Sciences, Sari, Iran. \\ 4. Department of Microbiology, School of Medicine, Isfahan University of Medical Sciences, Isfahan, Iran. \\ 5. Health Sciences Research center, Addiction Institute, Mazandaran University of Medical Sciences, Sari, Iran.
}

\begin{tabular}{|l|l|}
\hline $\begin{array}{c}\text { Use your device to scan } \\
\text { and read the article online }\end{array}$ & $\begin{array}{l}\text { Crtation Taghizadeh M, Javadian B, Rafiei A, Taraghian A, Moosazadeh M. Antimicrobial Resistance and Virulence of Salmo- } \\
\text { nella spp. From Foods in Mazandaran. Research in Molecular Medicine. 2019; 7(2):9-18. https://doi.org/10.32598/rmm.7.2.59 }\end{array}$ \\
doi https://doi.org/10.32598/rmm.7.2.59
\end{tabular}

\section{(c) (1) (s)}

Article Type:

Research Paper

Article info:

Received: 08 Mar 2019

Revised: 26 Mar 2019

Accepted: 15 Apr 2019

Keywords:

Salmonella spp,

Antimicrobial, Virulence gene, PCR

\begin{abstract}
A B S T RA C T
Background: Salmonella is the most important source of food-borne infections around the world. Human salmonellosis is also caused by the consumption of fresh fruit and vegetable salads contaminated with Salmonella spp. We aimed to detect Salmonella spp. in hamburgers, vegetable salads, and cream-filled pastries from various sources in Mazandaran and assess their pathogenicity and antimicrobial resistance.

Materials and Methods: A total of 90 samples, eg, hamburgers, vegetable salads, and creamfilled pastries ( 30 samples of each), were randomly collected. Biochemical and serological tests were performed to detect the Salmonella spp. Antimicrobial susceptibility tests were performed by the disc diffusion method and the virulent genes were examined using Polymerase Chain Reaction (PCR). All the examined Salmonella serovars in this study showed positive amplification for the virulence genes invA, spv, and viaB.

Results: Salmonella spp. were detected in 54 of the 90 samples based on biochemical tests. Of these, 46 isolates $(85.2 \%)$ were recovered by the $16 \mathrm{~S}-23 \mathrm{~S}$ rRNA PCR test, of which $19(41.4 \%)$ represented the S. typhimurium serotype, $15(32.7 \%)$ represented the $\mathrm{S}$. enteritidis serotype, and 2 (4.4\%) represented the S. typhi serotype. These Salmonella serotypes (19 S. typhimurium, 15 S. enteritidis, and $2 \mathrm{~S}$. typhi; 36 in total) were sensitive to all the tested antibiotics: Ampicillin, 22/36 (61.11\%); Streptomycin 22/36 (61.11\%); Cefotaxime 23/36 (63.88); Gentamycin 36/36 $(100 \%)$, and Tetracycline $36 / 36(100 \%)$. However, a few of these serotypes exhibited slight resistance to ampicillin $(4 / 36 ; 11.11 \%)$ and cefotaxime $2 / 36(5.55 \%)$.

Conclusion: These results would greatly help in understanding the prevalence of virulence genes and antibiotic sensitivity among Salmonella serovars in hamburgers, vegetable salads, and cream-filled pastries.
\end{abstract}

\footnotetext{
* Corresponding Author:

Behzad Javadian, MSc.

Address: Amol Faculty of Paramedics, Mazandaran University of Medical Sciences, Sari, Iran.

Phone: +98 (911) 9111254385

E-mail: B_j1347@yahoo.com
} 


\section{Introduction}

almonellosis is the infection of the intestinal epithelium, which is caused by the bacteria from the genus Salmonella. Salmonella spp. are the most important source of gastrointestinal tract and foodborne infections worldwide. Despite the global improvement in public health services, a noticeable increase in the incidence of human salmonellosis has been reported in many countries, including Iran [1]. S. enterica serotype Typhi is particularly related to humans, and is found in foods, mostly due to improper handling and hygiene [2]. Furthermore, the serotypes Enteritidis and Typhimurium have been isolated from humans, animals, vegetables, and meats (e.g. broilers and chicken) [3].

Human salmonellosis has also been found to be caused by the consumption of Salmonella-contaminated fresh fruits, vegetables, and vegetable salads [4]. The number of outbreaks associated with the consumption of contaminated products, especially those caused by Salmonella spp., has also increased [5]. Increasing reports of foodborne diseases, especially due to the secondary contamination of foods after their processing, has enhanced the issue of food safety concerns for consumers, producers, and other entities in the food industry [6].

Ready-to-eat (RTE) foods (red meat, poultry, seafood, and vegetables) vary widely across different countries according to their cultural and social backgrounds. Due to their widespread availability, negligible cooking time, and cheaper prices, they are very popular among people. Thus, contaminated RTE foods may also pose serious threats to public health $[7,8]$. Salmonella serovars have been reported in 645 raw and cooked food samples from Isfahan, one of the most populated provinces in Iran; Salmonella spp. have been detected in $43(6.66 \%)$ of these samples, among which S. enteritidis $(29 \%)$ was the most prevalent in raw foods [9]. Owing to the fact that these foods do not undergo further processing, the microbiological risks for the consumer from these products are also higher. Therefore, the presence of Salmonella spp. in food products is a significant food safety risk.

The virulence of Salmonella spp. is linked to a combination of plasmid and chromosomal factors. Different genes such as spv and inv have been identified as major virulence genes responsible for salmonellosis [10]. The chromosomal gene invA encodes a protein in the inner membrane that is necessary for the invasion of epithelial cells. On the other hand, the operon spvRABCD, which comprises five genes, is present on plasmids commonly associated with some Salmonella serotypes. One major function of the spv operon is to potentiate the systemic spread of the pathogen [11]. Additionally, the viaB locus encodes genes for the positive regulation (tviA), biosynthesis (tviBCDE), and export (vexABCDE) of the virulence (Vi) capsular polysaccharide [12].

So far, only a few studies about Salmonella-contaminated hamburgers, vegetable salads, and cream-filled pastries in Iran have been performed. Therefore, in this study, we considered the importance of detecting Salmonella spp. in these food products. The isolation and identification of Salmonella spp. and antimicrobial susceptibility analysis for the treatment of salmonellosis, which is very important to continually monitor the safety of fresh products and its impact on human health, were performed. We also evaluated the presence of the virulent genes invA, spv, and viaB by Polymerase Chain Reaction (PCR).

\section{Materials and Methods}

\section{Sample collection}

A total of 90 different food samples, 30 samples each, eg, of hamburgers, vegetable salads, and cream-filled pastries from factories, supermarkets, restaurants, and local confectioneries in Mazandaran, Iran were collected from April to June 2018. These samples were randomly collected, moved to the laboratory in an icebox, and analyzed within one hour of their purchase.

\section{Sample preparation}

The samples were examined for the presence of Salmonella by the Iranian National Standards method No. 1810, the method recommended by the Institute of Standards and Industrial Research of Iran (ISIRI) [13], and according to the ISO 6579 protocol [14]. For the isolation of the Salmonella spp., a 25-g portion of each sample was weighed aseptically in a sterile stomacher bag containing $225 \mathrm{~mL}$ of sterile buffered peptone water (BPW, Merck, Germany). BPW was used for the pre-enrichment of the isolates at $37^{\circ} \mathrm{C}$ for $18 \mathrm{~h}$. Then, $1 \mathrm{~mL}$ and $0.1 \mathrm{~mL}$ of this pre-enriched sample were inoculated into $10 \mathrm{~mL}$ of Rappaport-Vassiliadis-Soya (RVS), Merck broth, and $10 \mathrm{~mL}$ of Muller-Kauffmann Tetrathionate-Novobiocin (MKTTn, Merck) broth, respectively, followed by incubation at 42 and $37^{\circ} \mathrm{C}$ for $24 \mathrm{~h}$, respectively. 


\section{Isolation procedures}

Xylose lysine deoxycholate agar (XLD, Merck) was used as the selective isolation media; the cultures were incubated at $37^{\circ} \mathrm{C}$ for $24 \mathrm{~h}$. At least three characteristic colonies were picked from each plate and purified by streaking on Tryptone Soy Agar (TSA, Merck).

\section{Identification of the bacteria}

Indole production was tested by the inoculation of the cultures into SIM (Sulfide, Indole, Motility) medium overnight. The cultures were overlaid with five drops of Kovac's reagent (isoamyl alcohol, p-dimethylaminobenzaldehyde, and concentrated $\mathrm{HCl}$ ). Salmonella spp. are regarded as indole-negative organisms. Urease activity was tested on urea medium. Salmonella spp. are regarded as urease-negative organisms. Salmonella spp. produce $\mathrm{H} 2 \mathrm{~S}$ and an alkaline/acid reaction on TSI; the TSI agar used was produced by Oxoid. An oxidase test was also performed; the reagent comprised the active chemical N,N,N9,N9-tetramethyl-p-phenylenediamine hydrochloride (dissolved in dimethyl sulfoxide). Salmonella spp. are regarded as oxidase-negative organisms. A heavy suspension (MacFarland standard no. 4) of the organisms was prepared in $1.0 \mathrm{ml}$ of sterile $0.85 \%$ saline; $200 \mu \mathrm{l}$ of this suspension was dispensed into a test tube and a tablet of ONPG was added. The ONPG ( $\beta$-galactosidase) used was manufactured by Rosco Diagnostica, Taastrup, Denmark. Salmonella spp. are regarded as ONPG-negative organisms [15].

Serological identification of the salmonella isolates

The Salmonella isolates were subjected to serological identification according to the Kauffman-White Scheme for the determination of the somatic $(\mathrm{O})$ and flagellar $(\mathrm{H})$ antigens. The cultures were maintained as frozen stocks in brain heart infusion (BHI, Merck) broth supplemented with $20 \%$ glycerol at $-30^{\circ} \mathrm{C}[16]$.

\section{Antimicrobial susceptibility test}

The antibacterial susceptibility of the Salmonella isolates was determined using the disc diffusion technique, according to the instructions of the Clinical and Laboratory Standards Institute. The isolates were cultured in $10 \mathrm{~mL}$ of Mueller-Hinton (MH) broth (Merck, Germany) at $37^{\circ} \mathrm{C}$ for $24 \mathrm{~h}$. Overnight cultures, grown in MH broth (OD adjusted to $0.5 \mathrm{McF}$ arland unit), were swabbed evenly onto $\mathrm{MH}$ agar plates using sterile nontoxic cotton swabs and left to dry for 2-5 min. Then, antimicrobial discs were placed onto the plates, followed by incubation at $37^{\circ} \mathrm{C}$ for $24 \mathrm{~h}$. The discs used were: Ampicillin $(10 \mu \mathrm{g})$, Cefotaxime $(30 \mu \mathrm{g})$, Gentamycin $(10 \mu \mathrm{g})$, Streptomycin $(10 \mu \mathrm{g})$, and Tetracycline (30 $\mu \mathrm{g})$, (ROSCO, Denmark) [17].

\section{Detection of virulence genes using PCR}

DNA was extracted using the Qiagen DNA Extraction Kit, according to the manufacturer's instructions. The primer sequences and PCR conditions used for the study are listed in Table 1. The temperature conditions and time durations of the PCR reaction included: initial denaturation $\left(95^{\circ} \mathrm{C}\right.$ for 10 minutes), denaturation $\left(94^{\circ} \mathrm{C}\right.$ for $60 \mathrm{~s}, 30$ cycles), annealing $\left(58^{\circ} \mathrm{C}\right.$ for 90 seconds), extension $\left(72^{\circ} \mathrm{C}\right.$ for $\left.90 \mathrm{~s}\right)$, and final extension $\left(72^{\circ} \mathrm{C}\right.$ for 10 minutes), one cycle. The PCR products were electrophoresed on a $1.5 \%(\mathrm{w} / \mathrm{v})$ agarose gel containing the DNA Green Viewer stain (Qiagen, Germany) using the standard protocol.

Table 1. PCR primers for the amplification of the virulence genes

\begin{tabular}{|c|c|c|c|c|c|}
\hline Designation & Bacteria & Primer & Sequence $5^{\prime}-3^{\prime}$ & Size (bp) & Reference \\
\hline Genus & Salmonella spp. & 16S-23S rRNA & $\begin{array}{l}\text { TGTTGTGGTTAATAACCGCA } \\
\text { CACAAATCCATCTCTGGA }\end{array}$ & $572 \mathrm{bp}$ & [18] \\
\hline \multirow{3}{*}{$\begin{array}{l}\text { Salmonella } \\
\text { enterica serotypes }\end{array}$} & S. Typhimurium & $\operatorname{Inv} A$ & $\begin{array}{l}\text { GTGAAATTATCGCCACGTTCGGGCAA } \\
\text { TCATCGCACCGTCAAAGGAACC }\end{array}$ & $284 \mathrm{bp}$ & [19] \\
\hline & S. Enteritidis & Spv & $\begin{array}{l}\text { GCCGTACACGAGCTTATAGA } \\
\text { ACCTACAGGGGCACAATAAC }\end{array}$ & $250 \mathrm{bp}$ & [36] \\
\hline & S. Typhi & ViaB & $\begin{array}{l}\text { CACGCACCATCATTTCACCG } \\
\text { AACAGGCTGTAGCGATTTAGG }\end{array}$ & 738 bp & [37] \\
\hline
\end{tabular}


A 100-bp DNA ladder (Sinaclon BioScience, IRN) was used as the marker. The positive controls used were $\mathrm{S}$. enterica ATCC 13076, S. typhimurium ATCC 49416, S. enteritidis ATCC 13076, and S. typhi ATCC 8390. E. coli ATCC 25922 was used as a negative control $[18,19]$.

\section{Statistical analysis}

All measurements were performed in triplicate. For all analyses, $\mathrm{P}<0.05$ were considered statistically significant. The results of descriptive statistics, such as the abundance in terms of contamination rate in the samples and frequency of antibiotic resistance, are presented.

\section{Results}

Prevalence of Salmonella in different samples

Of the 90 isolates, 54 non-lactose-fermenting isolates $(60 \%)$ were considered as Salmonella spp. Salmonella spp. were the most prevalent in the hamburgers ( $48.14 \%$ incidence rate), followed by the cream-filled pastries and salads $(31.48 \%$ and $20.37 \%$ incidence rates, respectively).

\section{Serotyping of the Salmonella isolates}

Of 54 Salmonella-positive isolates, 46 (85.2\%) were recovered by the $16 \mathrm{~S}-23 \mathrm{~S}$ rRNA PCR analysis. Of these 46 isolates, 36 (78.26\%) represented the S. Typhimurium, S. Enteritidis, and S. Typhi serotypes, and 10 represented other Salmonella serotypes.

Three serotypes were detected from all the samples:19 samples $(41.4 \%)$ represented the S. Typhimurium serotype; 15 (32.7\%), the S. Enteritidis serotype; and 2 (4.4\%), the S. Typhi serotype, as stated in Table 2. As shown, S. Typhimurium was the most prevalent serotype in the hamburgers, $12(33.3 \%)$, followed by S. Enteritidis in the cream-filled pastries and hamburgers (6 $(16.66 \%)$ and $5(13.8 \%)$, respectively).

Table 2. Serotyping of the Salmonella isolates

\begin{tabular}{ccccc}
\hline \multirow{2}{*}{ Samples } & \multicolumn{4}{c}{ Isolated Serotypes (No. and \%) } \\
\cline { 2 - 5 } & S. Typhi & S. Typhimurium & S. Enteritidis & Total \\
\hline Hamburgers & $1(2.7)$ & $12(33.3)$ & $5(13.8)$ & $18(49.8)$ \\
\hline Cream-filled pastries & $1(2.7)$ & $4(11.11)$ & $6(16.66)$ & $11(30.47)$ \\
Salads & - & $3(8.33)$ & $4(11.11)$ & $7(19.44)$ \\
Total & $2(4.4)$ & $19(41.4)$ & $15(32.7)$ & $36(78.26)$ \\
\hline
\end{tabular}

Table 3. Antimicrobial susceptibility pattern of Salmonella isolates

\begin{tabular}{|c|c|c|c|c|}
\hline \multirow{2}{*}{ Antimicrobial Agent } & \multirow{2}{*}{ No. of Isolates Tested } & \multicolumn{3}{|c|}{ Antibiogram Pattern of the Salmonella Isolates (\%) } \\
\hline & & Resistant & Intermediate & Sensitive \\
\hline Ampicillin & 36 & 4/36 (11.11) & $10 / 36(27.78)$ & $22 / 36(61.11)$ \\
\hline Streptomycin & 36 & - & $14 / 36(38.89)$ & $22 / 36(61.11)$ \\
\hline Cefotaxime & 36 & $2 / 36(5.55)$ & $11 / 36(30.55)$ & $23 / 36(63.88)$ \\
\hline Gentamycin & 36 & - & - & $36 / 36(100)$ \\
\hline Tetracycline & 36 & - & - & $36 / 36(100)$ \\
\hline
\end{tabular}


1

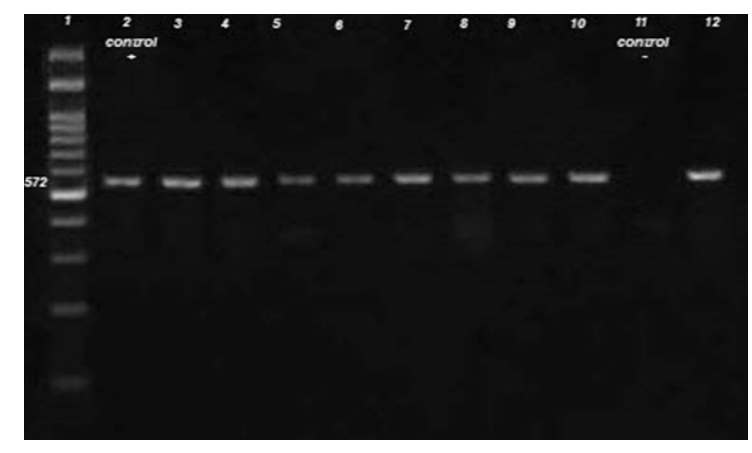

3

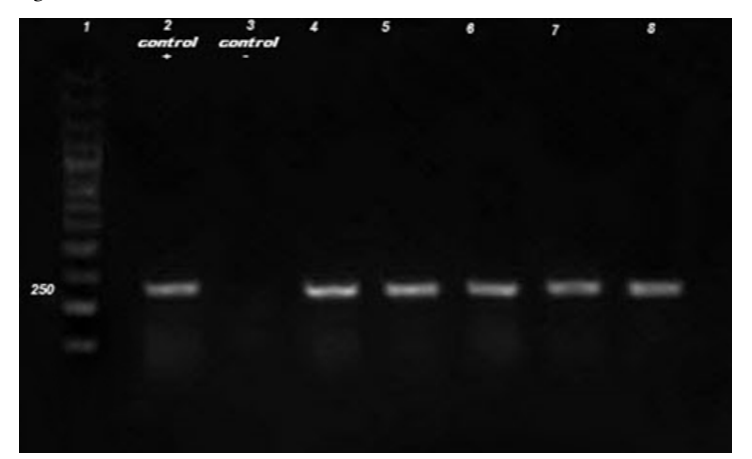

2

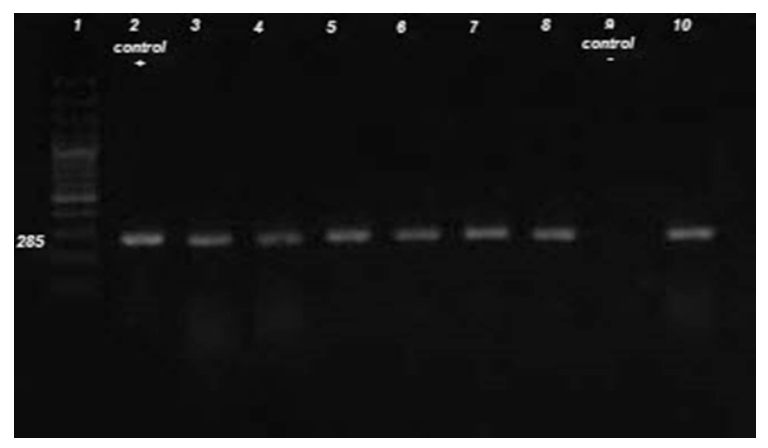

4

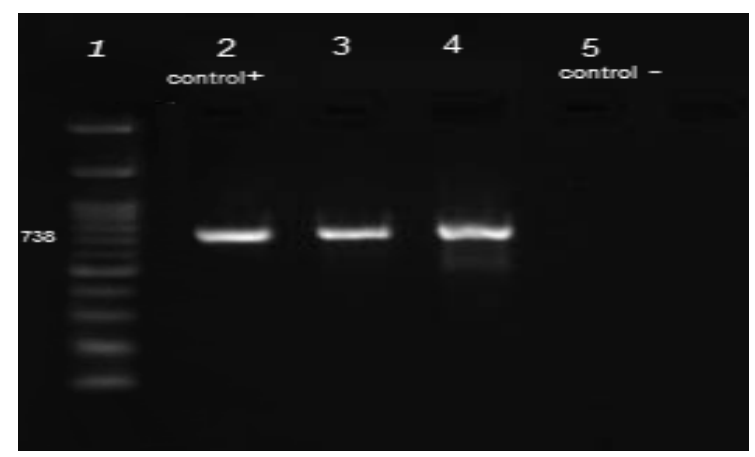

क $\mathrm{Rmm}$

Figure 1. Agarose gel electrophoresis of the amplified DNA

The specificity of the single PCR for the detection of: 1) 16S rRNA gene (572 bp); 2) invA (284 bp) gene; 3) spv gene (250 bp); and 4) viaB gene (738 bp).

Control+: Positive control; Control-: Negative control; 1, 100-bp DNA ladder: 1. Lanes 3-10 and 12; 2. lanes 3-8 and 10; 3. lanes 4-8; 4. lanes 3 and 4, Salmonella isolates

Antimicrobial sensitivity of the Salmonella isolates

Antibiotic sensitivity testing was performed for the 36 isolated Salmonella strains, which included the serotypes S. Enteritidis $(n=15), S$. Typhimurium $(n=19)$, and S. Typhi $(\mathrm{n}=2)$. As shown in Table 3, two antibiotics (gentamicin and tetracycline) were 100\% effective against all the isolates. In this study, the most resistance was seen in case of ampicillin $(4 / 36 ; 11.11 \%)$.

\section{Detection of virulence genes using PCR}

All the examined Salmonella serovars in this study showed positive amplification for the 16S rRNA, invA, spv, and viaB genes, as shown in Figure 1. The positive (S. typhimurium ATCC 14028 and S. enteritidis ATCC 13076) and negative controls (E. coli ATCC 25922) were used for the detection of the virulence genes in Salmonella spp. in this study.

\section{Discussion}

In the present study, Salmonella spp. were isolated from hamburger, cream-filled pastry, and vegetable salad samples (in 36 of the 46 recovered isolates; $78.26 \%$ ). In Iran, currently available data on the incidence of Salmonella serotypes in foods are limited. Three Salmonella serotypes, i.e. S. Typhi, S. Typhimurium, and S. Enteritidis (across a total number of $18(49.8 \%)$ isolates) were identified in the hamburger samples. The most and least abundant serotypes identified in this study were S. Typhimurium and S. Typhi, respectively. In contrast, other countries have reported the isolation of Salmonella spp. from hamburger with an incidence of $12.50 \%$; two samples $(2 \%)$ were contaminated with Salmonella spp. that represented the serogroup C2 (antigen O8) [20, 21].

Jorge Luiz Fortuna et al. (2012) have isolated Salmonella spp. from beef and chicken hamburgers and beef hamburgers in Brazil; of the 80 hamburger samples analyzed, 22 (27.5\%) were positive for Salmonella spp., ie, 10 beef (12.5\%), and 12 (15\%) chicken and beef hamburgers [22]. Similarly, Parra et al. (2002) have found that among 27 hamburger samples collected in the city of Maracaibo, Venezuela, comprising 18 beef hamburger samples and 9 chicken burger samples, 9 beef hamburger samples $(33.33 \%)$ were contaminated with the pathogen [23]. 
Corresponding to this result, Leal et al. (2008) have performed a study analyzing 60 hamburger samples, of which 30 were home-made and 30 were industrialized products; herein, Salmonella spp. were isolated from one home-made hamburger sample (1.66\%) [24].

Salmonella spp. are detected mainly in animal food products, including hamburgers prepared with beef alone or with a combination of beef and chicken. Hamburgers are extensively industrialized meat products consumed largely because of their easy preparation process and excellent sensory characteristics. Although fat and other ingredients may be included, the primary raw ingredient in hamburgers is minced beef. Pathogen growth and transmission via hamburgers are promoted by intensive handling and complex preservation issues during the preparation process. High probabilities of some kind of contamination have been perceived throughout the hamburger production process.

Apart from problems in handling, storing, and even the preparation and consumption of foods, agents such as specific organic compounds used in pastures, improper management techniques and transportation of animals, and inappropriate slaughter procedures (contamination in carcasses) may cause such Salmonella contamination [22]. In this sense, it is necessary to guarantee safe and contamination-free consumption by the microbiological assessment of the preparation methods and sanitation procedures associated with hamburger production.

Techniques developed to evaluate bacterial contamination during the production of food products, more specifically, those of animal origin, aim primarily at reducing the risk of food-borne diseases and testing the quality of these products. Considering the control and prevention of food poisoning outbreaks, the detection and characterization of Salmonella spp. in foods and water are very important.

Three serotypes of Salmonella were isolated from a total of 11 cream-filled pastry samples $(30.47 \%)$. Several studies in different countries were used as references. A study by Kotzekidou (2013) was conducted from 2001-2010 in Greece on pastry cream samples, in which the contamination levels of L. monocytogenes, S. aureus, Salmonella spp., E. coli, Enterobacteriaceae, were $20,12.5,28.6,25,35.3$, respectively [25]. In another study conducted in Hamedan, Iran, none of the samples were found to be contaminated with Salmonella spp. and Al-Jafaeri SM et al. (2013) have revealed that the contamination levels of S. aureus, E. coli, and
Salmonella spp. in pastry cream samples were 48,4 , and $8 \%$, respectively [26, 27].

Because of the increased health risks and reduced product quality, pastry contamination is economically detrimental to the food industry; this may lead to further multiplication of the Salmonella spp. to high infective doses. Accordingly, to avoid increasing contamination levels, the temperature of products that show quick putrefaction should be properly controlled.

Among the vegetable salad samples (containing lettuce, tomatoes, cucumber, green peppers, cabbage, carrot, and capsicum), in our study, Salmonella serotypes were identified in 7 (19.44\%) samples. The most abundant serotype identified in these samples was S. Enteritidis, and none of these samples were found to be contaminated with S. Typhi. The results in this study indicate that raw salad vegetables can be a potential source of Salmonella spp. In this study, S. Enteritidis was the most predominant serotype recovered from the leafy vegetables, namely lettuce and cabbage.

This is consistent with the finding reported in a previous study [28]. Furthermore, in another study in which salad samples were tested $(n=175)$, the overall prevalence of Salmonella spp., S. enteritidis, and S. typhimurium was 28,20 , and $14.3 \%$, respectively [29]. Bagged RTE raw salad vegetables are not subjected to any heating or freezing treatments, but are always subjected to washing-decontamination, dipping, and/or dewatering treatments before packaging and storage at low temperatures, distribution, and marketing [30].

Due to its clinical significance, determining the resistance of Salmonella spp. to antimicrobial agents is critical for the treatment of infections during outbreaks. The Salmonella isolates showed the most resistance against ampicillin (4/36 isolates; $11.11 \%$ ) and Cefotaxime (2/36 isolates; $5.55 \%)$, and were sensitive to the other two antibiotics, gentamicin and tetracycline $(100 \%)$. Similarly, a study in Malaysia has demonstrated that all the tested Salmonella strains $(n=240)$ were sensitive to gentamicin, tetracycline, and amoxicillin/ clavulanic acid (100\%) [31].

Previously, a study in China has demonstrated that all the tested Salmonella strains $(\mathrm{n}=83)$ were sensitive to amoxicillin/clavulanic acid, while 98.80 and $92.77 \%$ sensitivity was observed for gentamicin and tetracycline, respectively [32]. Abd-Elghany et al. (2015) have shown that $91.6 \%$ of all the tested isolates were resistant to ampicillin [33]. On the other hand, Hulaj et al. (2016) have reported that all the 
tested isolates were sensitive to ampicillin, and Lamas et al. (2016) have reported that all the tested Salmonella spp. isolates were susceptible to cefotaxime [34,35].

Hence, more attention should be focused on the supervision and control of the use of antimicrobial agents, typically in the agriculture and human health care sectors in Iran. The last few years have seen an increase and development in the use of PCR to rapidly and specifically detect Salmonella spp. The most common virulence gene present in Salmonella spp., the invA gene, has been used as a PCR target gene for detection of Salmonella spp. [32].

\section{Conclusion}

According to these results, it is clear that the frequency of the analysis of raw materials and the final products is not enough; a new standard for quality control checks of raw materials and the final food products should be developed. Thorough assessments of raw materials, education for personnel in the food industry, and the introduction of special biosecurity and biocontrol measures will aid the control of Salmonella infections. Such measures may limit the adverse effects of antibiotics and ensure the safety of food products and the environment.

The prevalence of virulence genes among screened the Salmonella serovars provided additional evidence on the risk of food-borne virulent salmonellosis. Finally, the obtained data provide a more accurate profile for understanding the dangerous spread of virulent Salmonella genotypes and antibiotic resistance among Salmonella serovars. Such data also facilitate the planning and application of biosecurity programs, in addition to the establishment of bio-control measures to control Salmonella infections caused by contaminated foods.

\section{Ethical Considerations}

\section{Compliance with ethical guidelines}

All ethical principles were considered in this article.

Funding

This study supported by Mazandaran University of Medical Sciences.

\section{Authors contribution}

Analysis, writing the manuscript: Alireza Rafiei; Approve of the manuscript: Azadeh Taraghian; Verified the analytical methods: Mahmood Moosazade.

\section{Conflict of interest}

The authors declared no conflict of interest.

\section{Acknowledgements}

The authors appreciate the Laboratory Technical Officers, Dr. Zainal-Abedin Babaei and Dr. Laleh Karimzadeh (Food Quality Control Laboratory, Mazandaran University of Medical Sciences, Sari, Iran), Dr. Reza Valadan (Molecular and Cell biology Research Center, and Faculty of Medicine, Mazandaran University of Medical Sciences, Sari, Iran) for providing laboratory facilities and their valuable support.

\section{References}

[1] Ochiai RL, Acosta CJ, Danovaro-Holliday MC, Baiqing D, Bhattacharya SK, Agtini MD. A study of typhoid fever in five Asian countries: Disease burden and implications for controls. Bull World Health Organ. 2008. 86(4):260-8. [DOI:10.2471/BLT.06.039818] [PMID] [PMCID]

[2] Che YH, Li Y, Slavik M, Paul D. Rapid detection of Salmonella typhimurium in chicken carcass wash water using an immunoelectrochemical method. J Food protec. 2000; 63(8):1043-8. [DOI:10.4315/0362-028X-63.8.1043] [PMID]

[3] Rabsch W, Tschäpe H, Bäumler AJ. Non-typhoidal salmonellosis: Emerging problems. Microbe Infect. 2001; 3(3):23747. [DOI:10.1016/S1286-4579(01)01375-2]

[4] O'mahony MJ, Cowden B, Smyth D, Lynch M, Hall B, Rowe EL, et al. An outbreak of Salmonella saint-paul infection associated with beansprouts. Epidemiol Infect. 1990; 104(2):229-35. [DOI:10.1017/S0950268800059392] [PMID] [PMCID]

[5] Hazards EP. Scientific opinion on the risk posed by pathogens in food of non-animal origin. Part 2 (Salmonella and norovirus in leafy greens eaten raw as salads). EFSA J. 2014; 12(3):1-118. [DOI:10.2903/j.efsa.2014.3600]

[6] Reij M, Den Aantrekker ED, ILSI Europe Risk Analysis in Microbiology Task Force. Recontamination as a source of pathogens in processed foods. Int J Food microbiol. 2004; 91(1):1-11. [DOI:10.1016/S0168-1605(03)00295-2]

[7] Mosupye FM, von Holy A. Microbiological quality and safety of ready-to-eat street-vended foods in Johannesburg, South Africa. J Food Protect, 1999. 62(11):1278-84. [DOI:10.4315/0362-028X-62.11.1278] [PMID]

[8] Kaneko KI, Hayashidani H, Ohtomo Y, Kosuge J, Kato M, Takahashi K, et al. Bacterial contamination of ready-to-eat foods and fresh products in retail shops and food factories. J Food Protect. 1999; 62(6):644-9. [DOI:10.4315/0362028X-62.6.644] [PMID]

[9] Jalali M, Abedi D, Pourbakhsh SA, Ghoukasin K. Prevalence of salmonella spp. in raw and cooked foods in Isfahan- 
Iran. J Food safety. 2008; 28(3):442-52. [DOI:10.1111/j.17454565.2008.00122.x]

[10] Sabbagh SC, Forest CG, Lepage C, Leclerc JM, Daigle F. So similar, yet so different: Uncovering distinctive features in the genomes of salmonella enterica serovars Typhimurium and Typhi. FEMS Microbiol Letters. 2010; 305(1):1-3 [DOI:10.1111/j.1574-6968.2010.01904.x] [PMID]

[11] Darwin KH, Miller VL. Molecular basis of the interaction of salmonella with the intestinal mucosa. Clin microbiol Revews. 1999; 12(3):405-28. [DOI:10.1128/CMR.12.3.405] [PMID] [PMCID]

[12] Virlogeux I, Waxin H, Ecobichon C, Popoff MY. Role of the viaB locus in synthesis, transport and expression of salmonella typhi Vi antigen. Microbiology. 1995. 1995(141):303947. [DOI:10.1099/13500872-141-12-3039] [PMID]

[13] Institute of Standards and Industrial Research of Iran (ISIRI). Microbiology of food and animal feeding stuffs- horizontal method for the detection of Salmonella spp. National Standard No. 1810 [Internet]. 2014 [Updated 2019 Dec 3]. Available from: http://standard.isiri.gov.ir/StandardView.aspx?Id=41860

[14] International Standards Organization (ISO). Microbiology of food and animal feeding stuffs - Horizontal method for the detection of Salmonella, in ISO 6579:2002(E). Geneva: International Standards Organization; 2002.

[15] Cowan ST, Steel KJ. Manual for the identification of medical bacteria. New York: Manual for the Identification of Medical Bacteria. 1965.

[16] Kauffmann F. [Serological diagnosis of salmonella-species. Kauffmann-White-Schema. Serological diagnosis of salmonella-species (German)]. Copenhagen: Kauffmann-WhiteSchema; 1972.

[17] Patel JB, Cockerill FR, Bradford PA. Performance standards for antimicrobial susceptibility testing; Twenty-Fifth informational supplement. Clin Lab Standards Inst. 2015; 35(3):29-50.

[18] Lin C, Tsen H. Use of two 16S DNA targeted oligonucleotides as PCR primers for the specific detection of Salmonella in foods. J Applied Bacteriol. 1996; 80(6):659-66. [DOI:10.1111/j.1365-2672.1996.tb03271.x] [PMID]

[19] Bozorgmehri Fard MH, Hassanzadeh M, Emaddi Chashni $\mathrm{SH}$, Mirzaie S. Characterization of the Salmonella isolates from backyard chickens in north of Iran, by serotyping, multiplex PCR and antibiotic resistance analysis. Arch Razi Inst. 2009; 64(2):77-83.

[20] Yörük Ng, Güner A. Control of fermented sausage, salami, sausage, and hamburger meatballs produced in meat production facilities applying the ISO food security system for food pathogens. Turkish J Veterinary Animal Sci. 2017; 41(3):337-44. [DOI:10.3906/vet-1606-97]

[21] Sharafati Chaleshtori R, Mazorii Arani N, Taghizadeh M, Sharafati Chaleshtori. Antibiotic resistance pattern of salmonella isolated from hamburgers and detection of their sensitivity to some essential oils. J Mazandaran Univ Med Sci. 2017; 27(148):136-42.

[22] Fortuna JL, do Nascimento ER, Franco RM. Detection of Salmonella spp in hamburgers: A comparison between modified standard and salmocyst method. Int J Food Safety. 2012; 14:104-12.

[23] Parra K, Pinero MP, Narvaez C, Uzcátegui S, de Moreno LA, Huerta-Leidenz N. [Evaluacion microbiologica y fisicoquimico de hamburguesas congeladas, expendidas en Maracaibo, estado Zulia, Venezuela (Spanish)]. Revista Científica de la Facultad de Ciencias Veterinarias. 2002; 12(6):715-21.

[24] Valero Leal K, Al Safadi Chaar S, Bermúdez Ayala A, Ávila Roo Y, Sandrea Toledo L, García Urdaneta A. [Comparación de la calidad microbiológica de hamburguesa de pollo elaborada en forma artesanal e industrial (Spanish)]. Revista Científica. 2008; 18(5):624-30.

[25] Kotzekidou P. Microbiological examination of ready-toeat foods and ready-to-bake frozen pastries from university canteens. Food Microbiol. 2013; 34(2):337-43. [DOI:10.1016/j. fm.2013.01.005] [PMID]

[26] Pajohi-alamoti M, Rezaei A, Mahmoudi R. Microbial contamination of pastry cream: Evidence from Iran. Arch Hygiene Sci. 2016; 5(3):207-13.

[27] Al-Jafaeri SM, Madi NS, Nahaisi MH. Incidence of pathogenic bacteria in cakes and tarts displayed for sale in tripoli, libya, world academy of science, engineering and technology. Int J Biol, Biomol, Agricultural, Food Biotechnol Engineer. 2013; 7(3):210-4.

[28] Lin C, Chiu C, Chu C, Huang Y, Lin T, Ou JT. A multiplex polymerase chain reaction method for rapid identification of Citrobacter freundii and Salmonella species, including Salmonella Typhi. J Microbiol, Immunol Infect. 2007; 40(3):2226.

[29] Nillian E, Ching CL, Fung PC, Robin T, Anyi U, Chilek TZ, et al. Simultaneous detection of Salmonella spp., Salmonella enteritidis and Salmonella Typhimurium in raw salad vegetables and vegetarian burger patties. Food and Nutrition Sciences. 2011; 2(10):1077. [DOI:10.4236/fns.2011.210144]

[30] Schlimme DV. Marketing lightly processed fruits and vegetables. HortScience. 1995; 30(1):15-7. [DOI:10.21273/ HORTSCI.30.1.15]

[31] Thung TY, Radu S, Mahyudin NA, Rukayadi Y, Zakaria $Z$, Mazlan N, et aL. Prevalence, virulence genes and antimicrobial resistance profiles of Salmonella serovars from retail beef in Selangor, Malaysia. Front Microbiol. 2018; 8:2697. [DOI:10.3389/fmicb.2017.02697] [PMID] [PMCID]

[32] Dong P, Zhu L, Mao Y, Liang R, Niu L, Zhang Y, et al. Prevalence and profile of Salmonella from samples along the production line in Chinese beef processing plants. Food Control. 2014; 38:54-60. [DOI:10.1016/j.foodcont.2013.09.066]

[33] Abd-Elghany SM, Sallam KI, Abd-Elkhalek A, Tamura T. Occurrence, genetic characterization and antimicrobial resistance of Salmonella isolated from chicken meat and giblets. Epidemiology \& Infection. 2015; 143(5):997-1003. [DOI:10.1017/S0950268814001708] [PMID]

[34] Hulaj B, Cabeli P, Goga I, Taylor N, Hess C, Hess ML. Survey of the prevalence of Salmonella species on laying hen farms in Kosovo. Poultry Science. 2016; 95(9):2030-7. [DOI:10.3382/ps/pew149] [PMID]

[35] Lamas A, Fernandez-No IC, Miranda JM, Vázquez B, Cepeda A, Franco CM. Prevalence, molecular characterization and antimicrobial resistance of Salmonella serovars isolated 
from northwestern Spanish broiler flocks (2011-2015). Poultry Science. 2016; 95(9):2097-105. [DOI:10.3382/ps/pew150] [PMID]

[36] Akbarmehr J. A survey on the prevalence of poultry salmonellosis and detection of different Salmonella serovars isolated from poultry in broiler chicken farms. African J Microbiol Res. 2011; 5(32):5950-4. [DOI:10.5897/AJMR11.996]

[37] Kumar S, Balakrishna K, Batra H. Detection of Salmonella enterica serovar Typhi (S. Typhi) by selective amplification of invA, viaB, fliC-d and prt genes by polymerase chain reaction in mutiplex format. Lett Appl Microbiol. 2006; 42(2):14954. [DOI:10.1111/j.1472-765X.2005.01813.x] [PMID] 
This Page Intentionally Left Blank 